تاثير تدريبات خاصة باستخدام الحبال المطاطية لتطوير التحمل الخاص

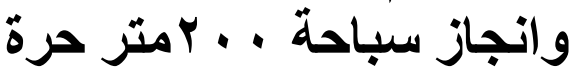

أد. موا هب ميد

P-ISSN: 199Г-..๑1

E-ISSN: $\Gamma V \cdot \Lambda-\mu \varepsilon O \varepsilon$

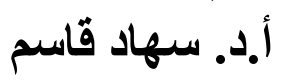

Dr_suhad@yahoo.com
أ.د. عدي طارق

الملخص الإنجاز العالي دحط انظار أهد

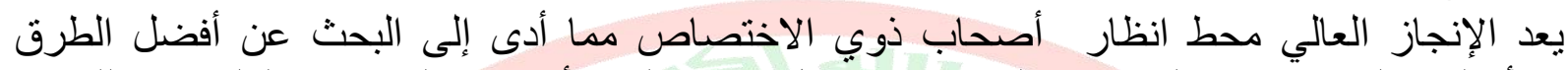

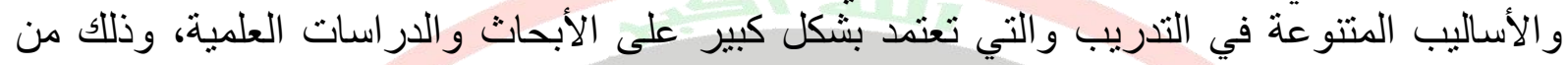

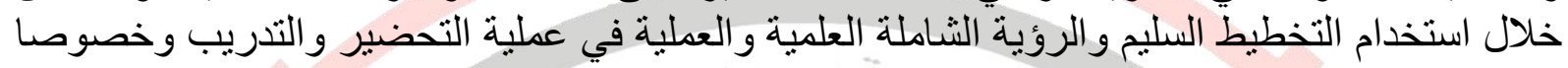

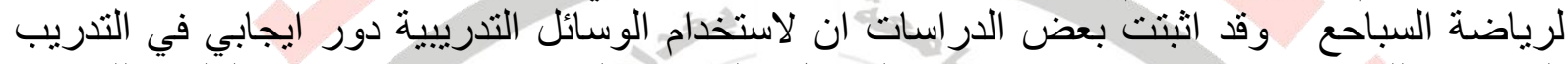

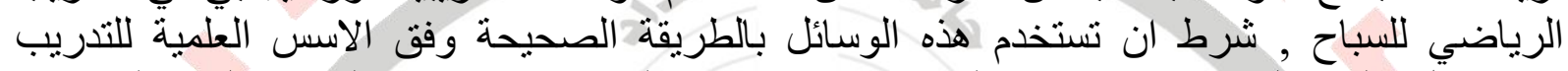

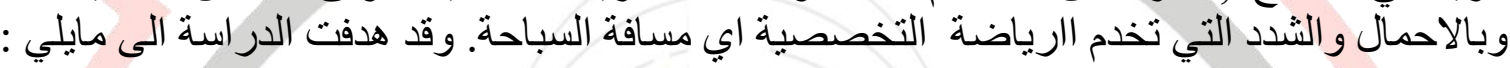

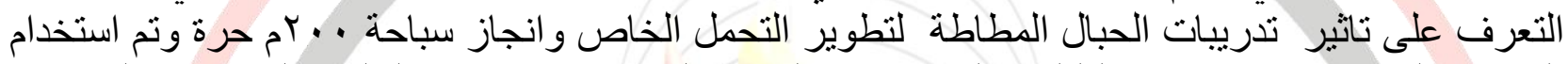

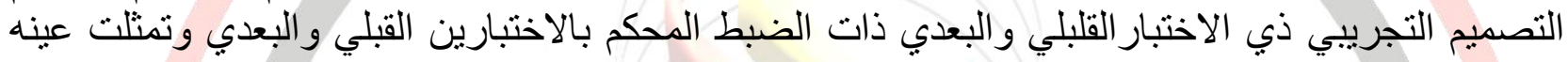

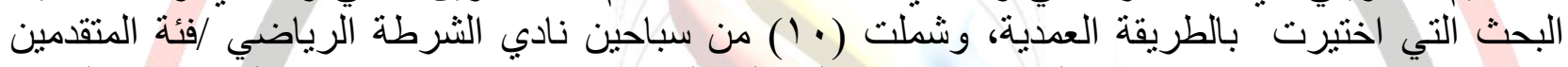

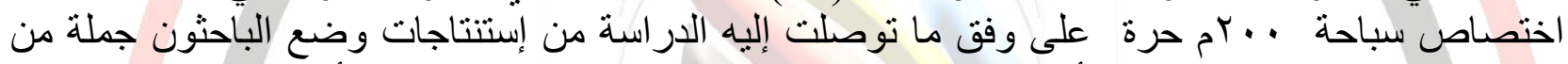

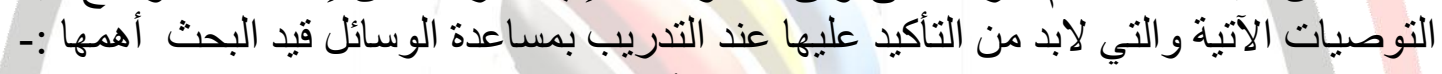

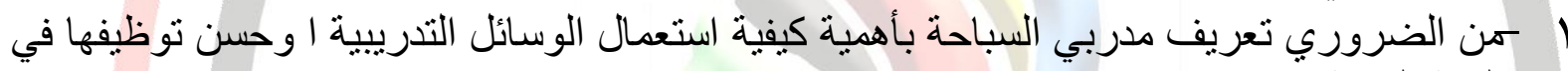
البيئة المائية المروي

ץ -لابد من التأكيد على توفير الأدوات الوسائل التدريبية التي تتسجم مع عمر وجنس السباحين

$$
\text { وخصوصية السباحة الحرة عند استعمالها في التدريب . }
$$

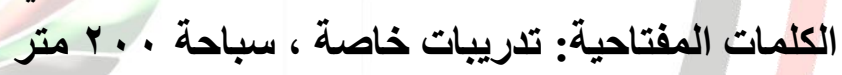

\section{The effect of special exercises using rubber ropes to develop special endurance and achieve a r. -meter freestyle swimming}

\section{Research Summary}

Swimming has now become the focus of attention of specialists, which has led to the search for the best methods and various methods of training, which rely heavily on scientific research and studies, through the use of proper planning and a comprehensive scientific and practical vision in the preparation and training process for this game. Some studies have proven that The use of training methods has a positive role in the athletic training of the swimmer, provided that these methods are used in the correct way according to the scientific principles of training and with the loads and stresses that serve the specialized activity, i.e. the swimming distance. The study aimed at the follow

1- Preparing exercises using elastic ropes

$r$ - Knowing the effect of elastic rope exercises to develop special endurance and achieve r. . m swimming

Free. An experimental design with a tightly controlled heart and post test was used for the pre and post tests, and the research sample was chosen by the intentional method. Conclusions The researchers put forward a set of the following recommendations, which must be 
emphasized when training with the help of the means under consideration, the most important of which

1- It is necessary to introduce swimming coaches to the importance of how to use training methods and how to properly use them in the water enviro

$r$-Emphasis must be placed on providing tools and training means that are consistent with the age and gender of swimmers and the specificity of free swimming when used in training.

Key words: special trainings, swimming $r \cdots m$

$$
\text { ا } 1 \text { - } 1 \text { مقدمة البحث وأهميته: }
$$

اتجهت الدول المتقدمة في مجال السباحة إلى توجيه طاقاتها و إمكاناتها وقدر اتها البشرية و المادية و العلمية

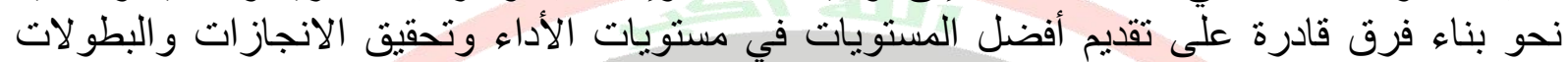

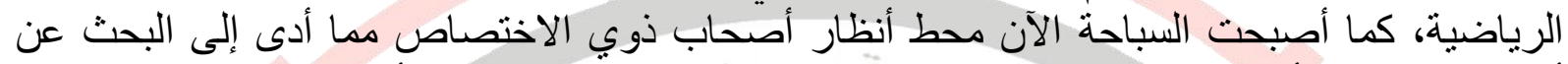

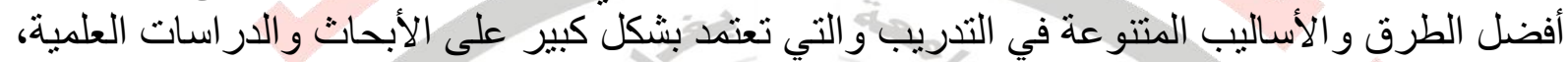

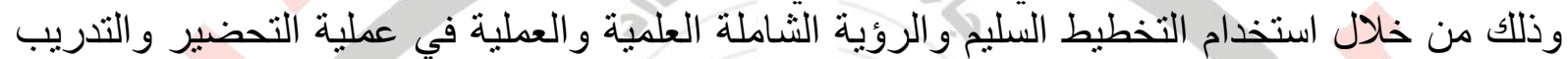

وفي الفترة الأخيرة تنافست الدراسات وبحوث تخص السباحة التنافسية بهدف إيجاد وابتكار الوسائل

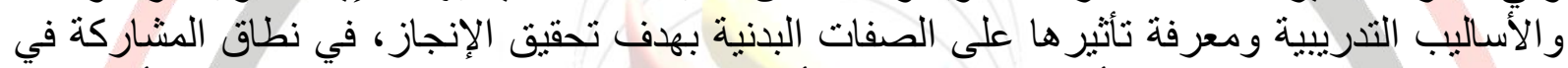

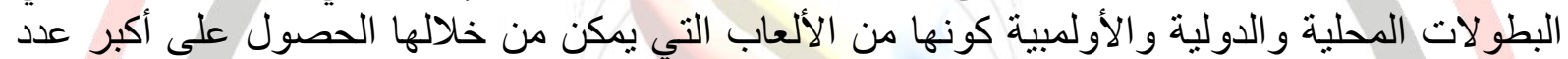

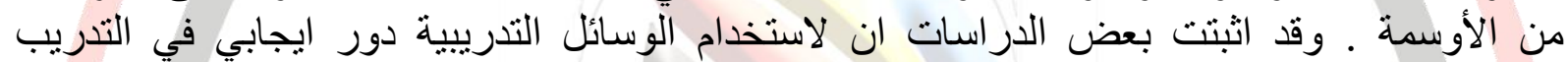
الرياضي للسباح , شرط ان تستخدم هذه الوسائل بالطريقة الصحيحة وفق الاست الإنس العلمية للتدريب

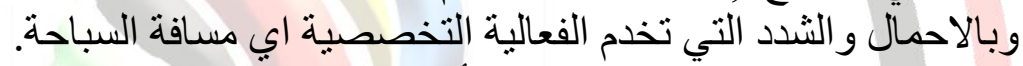

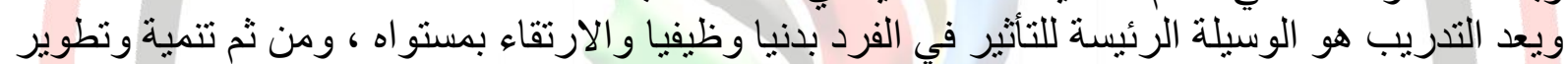

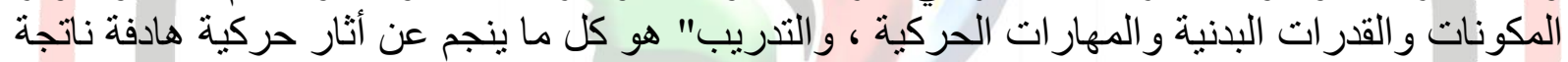

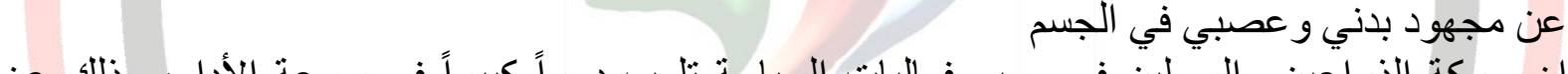

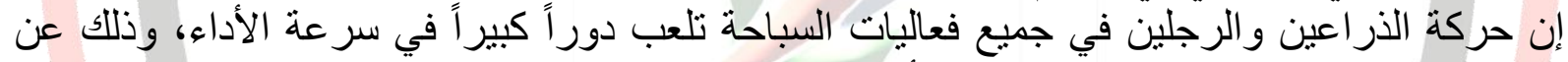

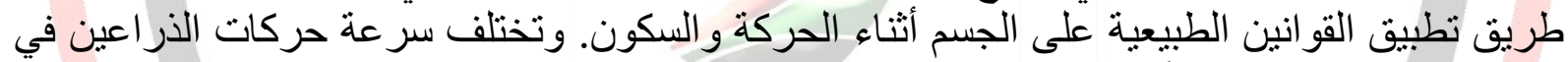

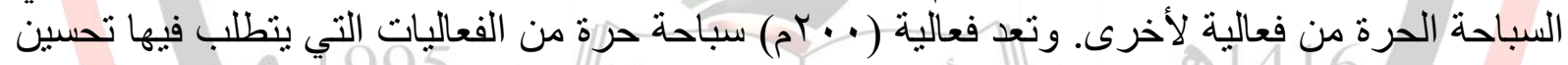

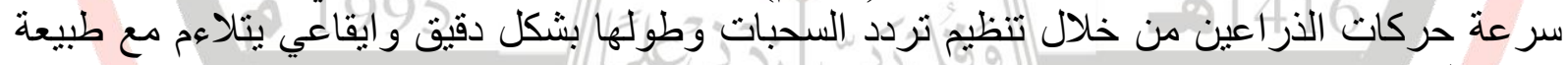
مسافة السباق

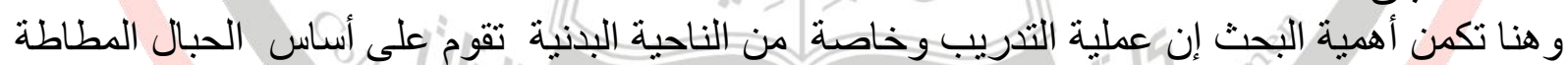

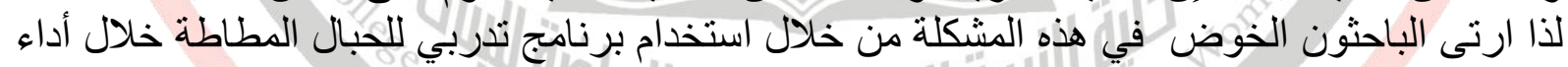

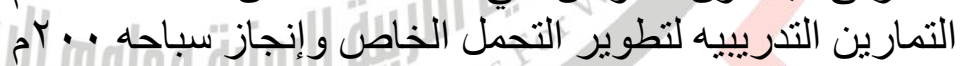

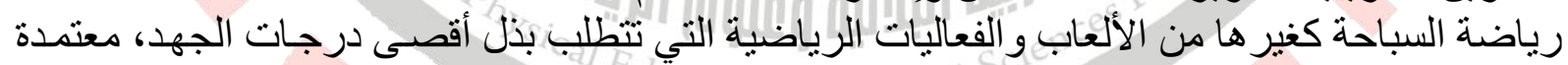

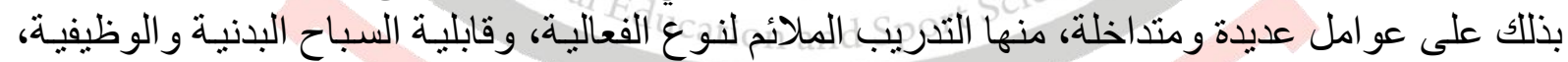

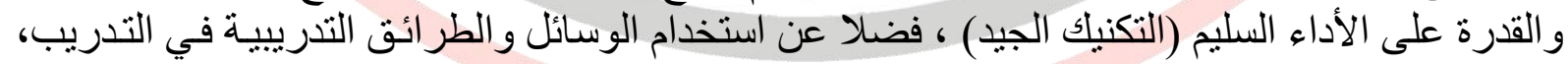

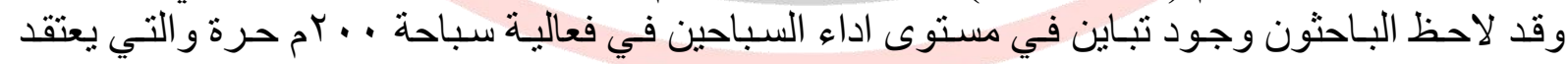

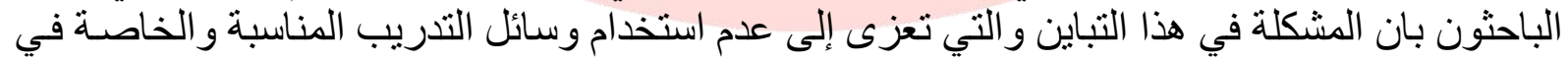

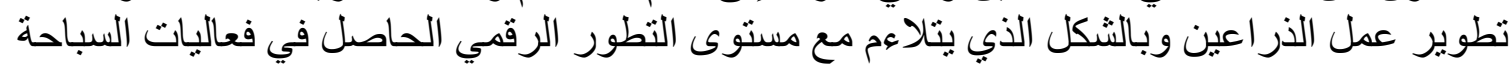

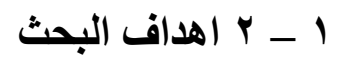
ا ـ اعداد تدريبات مقترحة باستخدام الحبـال المطاطة لتطوير التحمل الخـاص وانجاز سباحة . . ب متر 


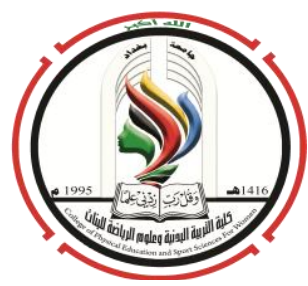

\section{مجلة الرياضة المعاصرة}

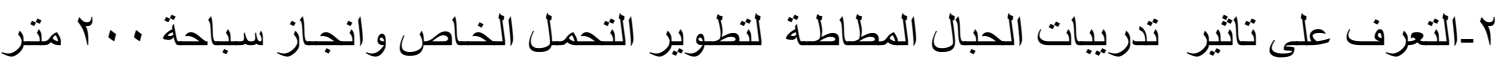
حرة.

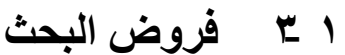

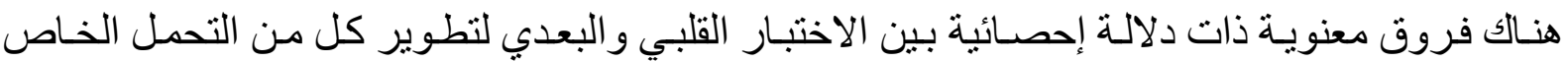
و انجاز سباحة . . r مثر حرة ـ ـ ولصالح الاختبار البعدي

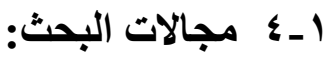

1 ـ ـ ـ ا : : المجال البشري: عينة من سباحي نادي الثرطة الرياضي / البئة المتقدمين

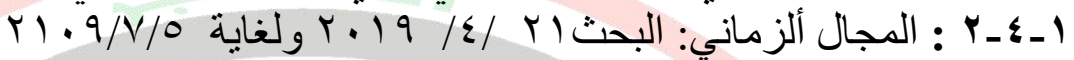

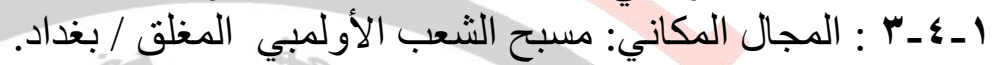

\section{r r r r r البهج البحث وإجراءاته الميدانية:}

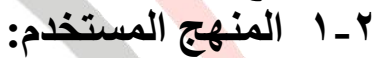

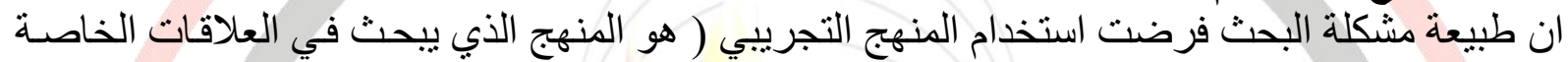

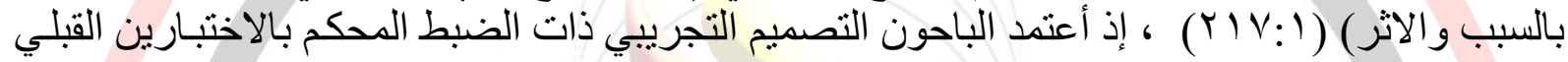

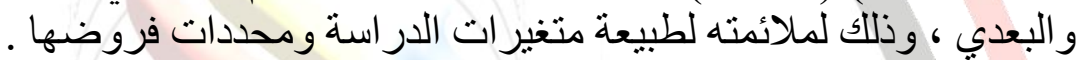

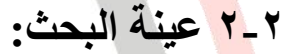

تم اختبار عينة البحث بالطريقة العدية، وشملت (• (1) من سباحين نادي الثرطة الرياضي /فئة

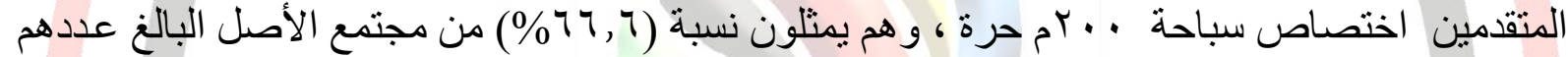
(10) سباحاً. وبناءا على خصائص عينة البحث قام الباحثّون باجر اء التجانس للأفر اد عينة البحثن، وكما

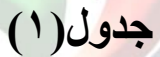

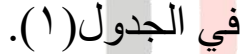

يبين قيمة معامل الاختلاف لمتغيرات الطول والعمر والوزن لأفراد عينة البحث

\begin{tabular}{|c|c|c|c|c|}
\hline 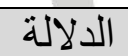 & قيمة معامل الاختلاف & $\varepsilon$ & سلح - ( & المتغير ات \\
\hline دال &., 70 & $\therefore, r \leqslant Y$ & 174 & الطول /سم \\
\hline دال & $1, Y M$ & $0,1 \wedge \varepsilon<=$ & $19,1 \leqslant$ & العمر 11 4 \\
\hline دال & $\therefore, \mathrm{VO}$ & $-3,90$ & 71 & 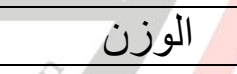 \\
\hline
\end{tabular}

r r r الوسائل والأدوات المستخدمة في البحث :-

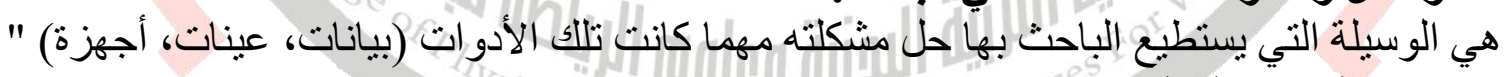

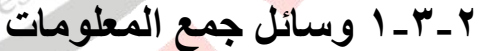
المر اجع العربية والاجنبية. شبكة المعلومات الدولية (الانترنيت).

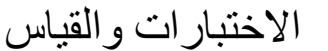

r r_r_r الأجهزة والأدوات المستخدمة بالبحث:

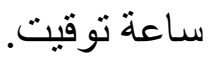




$$
\begin{aligned}
& \text { شريط قياس الكتروني. } \\
& \text { حبال مطاطية نوع speedo. ( لون الاسود شدة مقاومته ( } 9 \text { ـ ؟, • ب كغم)) }
\end{aligned}
$$

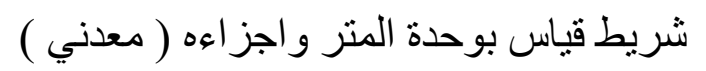

$$
\begin{aligned}
& \text { r r- }
\end{aligned}
$$

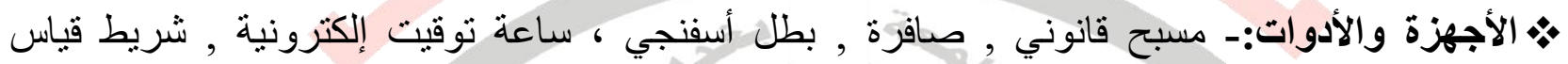

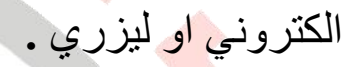
•خ طريقة الأداء:- عند سماع الصافرة ينطلق السباح بأقصى سر عة سباحة ولمدة (0 ؛ ثنانية. • شروط الآداء:- البدء في السباحة يكون من الأسفل مع وضع البطل الأسفنجي بين الرجلين والسباحة باستخدام الأطراف العليا فقط .

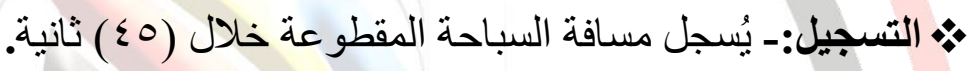
وحدة القياس :- المتر وأجز اءه

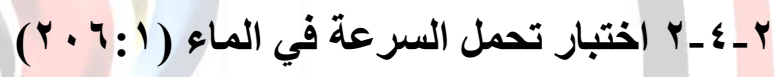

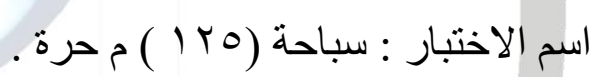

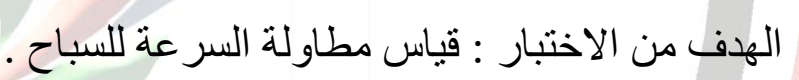

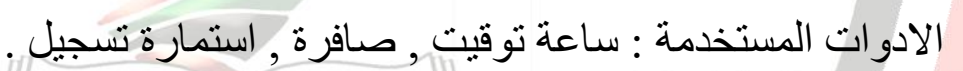

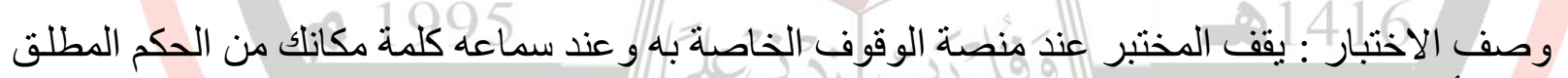

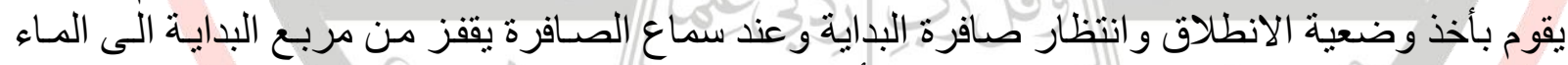

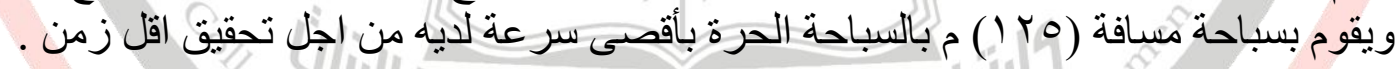

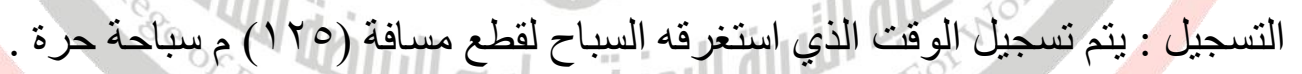

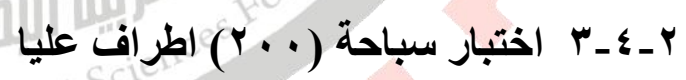

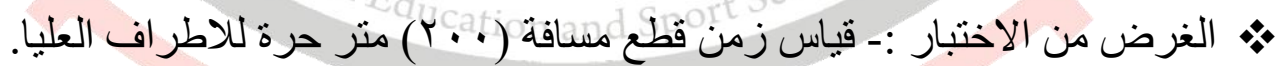

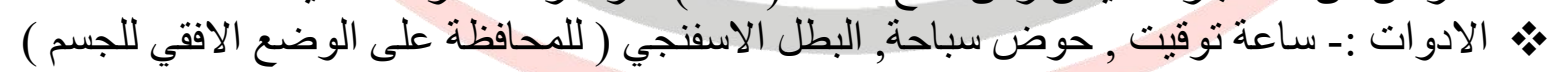

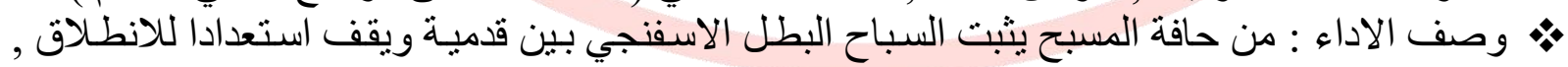

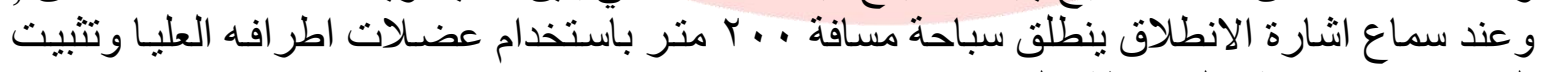
القدمين دون حركة و المحافظة على استقامتها.

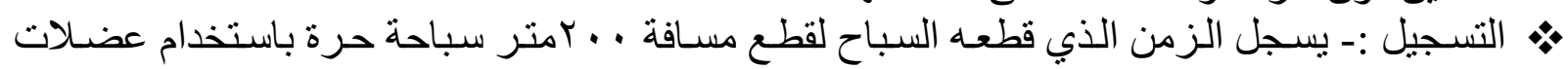
الاطر اف العليا فقط. 


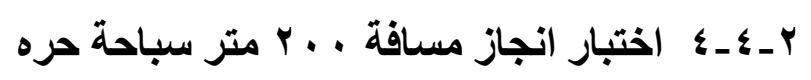

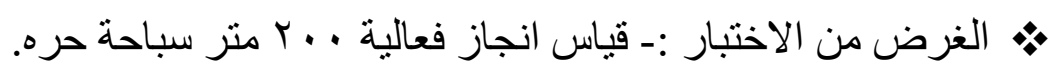
• ه الأدوات : ساعة توقيت, حوض سباحة.

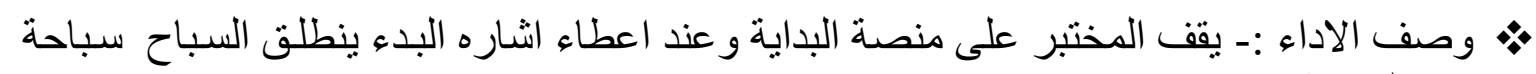
حرة لمسافة ... ب م. بقال

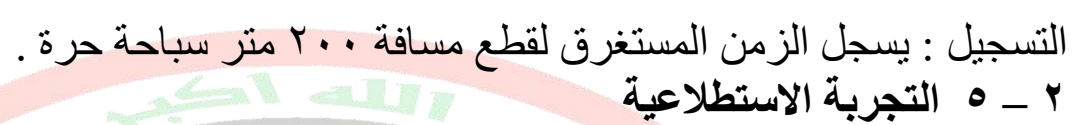

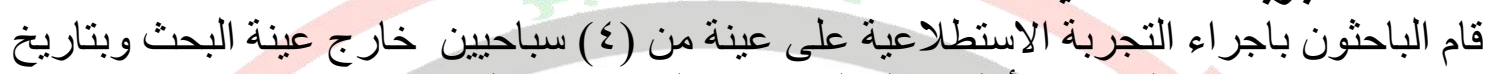

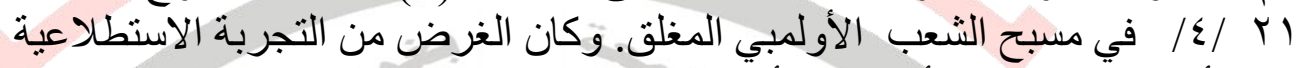

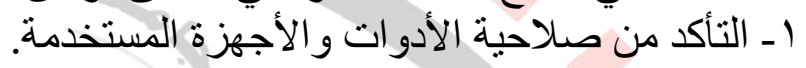

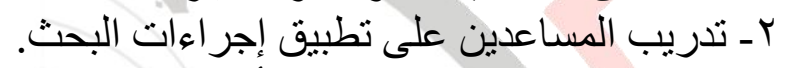

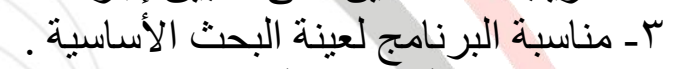

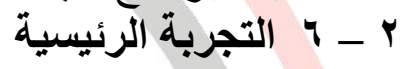
r-r

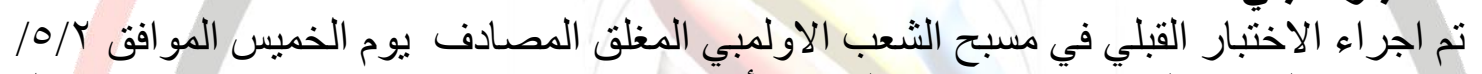

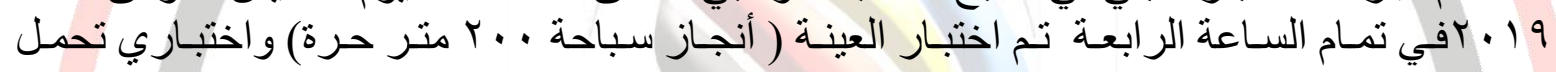
الخاص

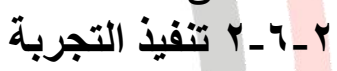

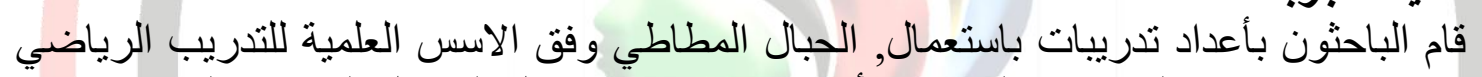

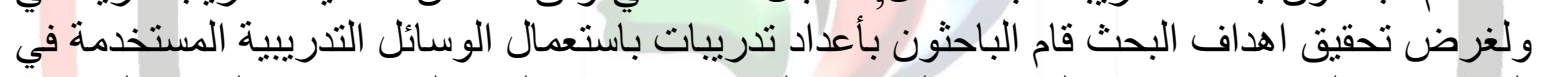

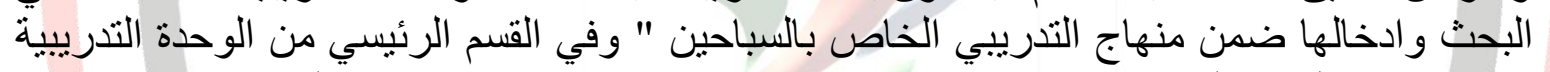

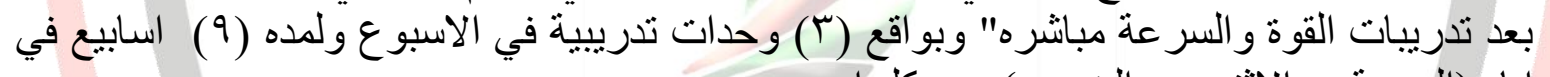

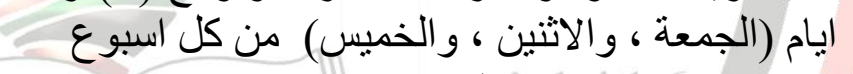

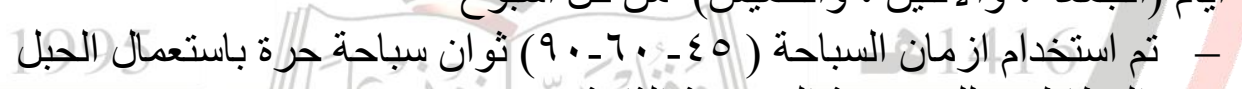
المطاطي وللمجمو عة التجريبية الثنانية.

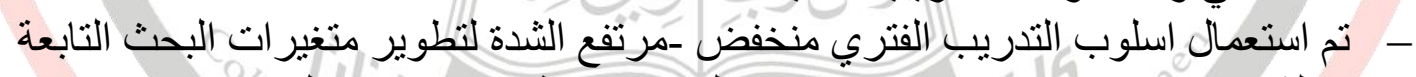

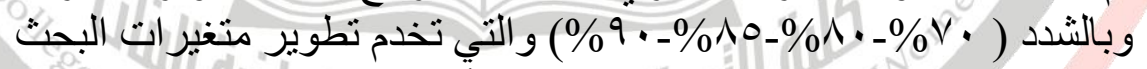

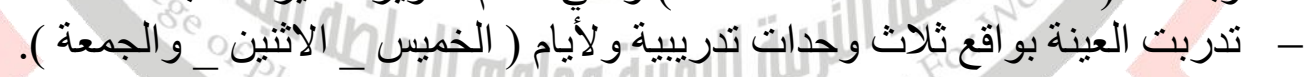

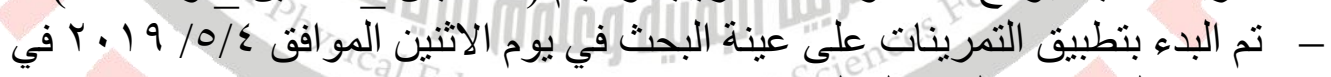

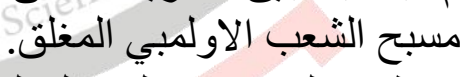

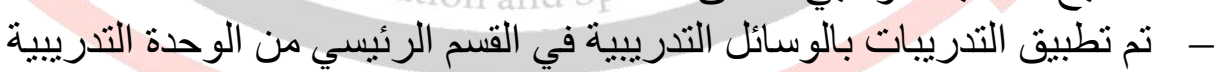

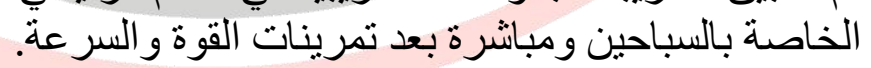

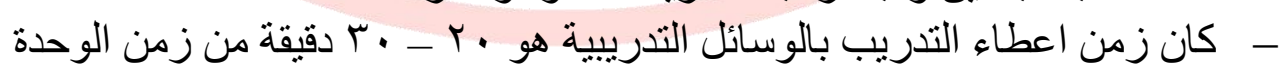

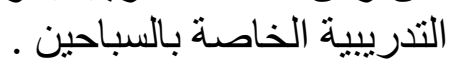

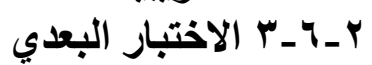

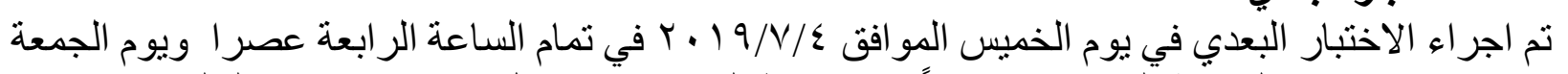

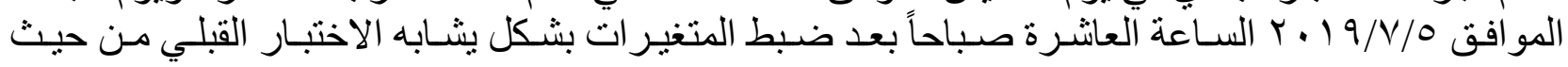
ظروف الاختبار و الزمان و المكان. 


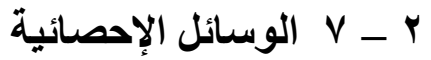

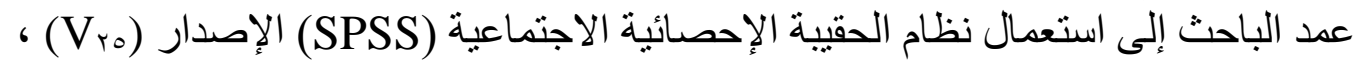 \\ (statistical package for social sciences)}

\section{r - عرض النتائج وتحليلها ومناقتشتها :-}

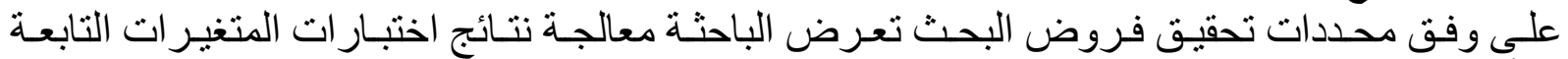

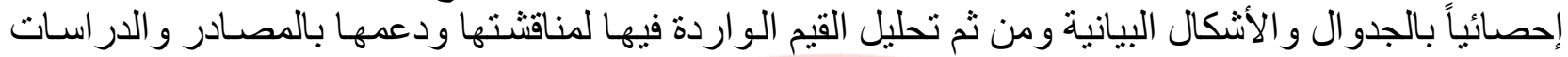

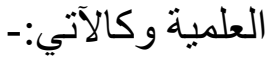

rـ ا عرض نتائج اختبارات التحمل الخاص القبلية والبعدية لمجموعات البحث

جدول (r) (1) (1) (1) (1)

يُيين نتائج أختبار (t-test) الاختبار ات القبلية والبعدية للتحمل الخاص

\begin{tabular}{|c|c|c|c|c|c|c|c|c|c|c|c|}
\hline \multirow{2}{*}{ 牙 } & \multirow{2}{*}{$\begin{array}{c}\text { (Sig } \\
\text { (Sig } \\
\end{array}$} & \multirow{2}{*}{ المحسو } & \multirow[b]{2}{*}{ ع ف } & \multirow[b]{2}{*}{ فَت } & \multicolumn{2}{|c|}{ الاختبار ألبعدي } & \multicolumn{2}{|c|}{ 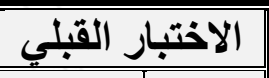 } & \multirow{2}{*}{\multicolumn{3}{|c|}{ الاختباران وعدد العينة }} \\
\hline & & & & & $\varepsilon \pm$ & سَ س & $\varepsilon \pm$ & سَ س & & & \\
\hline دال - - & $\cdots 9$ & $\varepsilon, V \leqslant 0$ & $r, \cdot V \varepsilon$ & $\varepsilon, \varepsilon$ & $r, \cdot V \varepsilon$ & or, $\varepsilon$ & $r, q r v$ & $\varepsilon \wedge$ & 0 & تج & تحمل القوة \\
\hline دال & $\cdots r$ & $v, v \backslash \Lambda$ & $\cdot, .9$ & $\cdot, T M$ & 9 & $1, \varepsilon \cdot r$ & $\cdot, \cdot V \leqslant$ & {$[1, V) \leqslant$} & 0 & تج & في الممل السر عة (دقية) \\
\hline
\end{tabular}

تبين نتائج الاختبار ات القبلية والبعدية التطور والتحسن لقدرتي التحمل الخاص لاى سباحي ، ولصالح

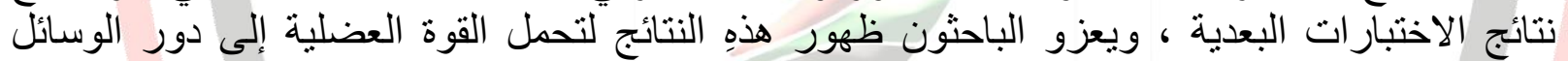

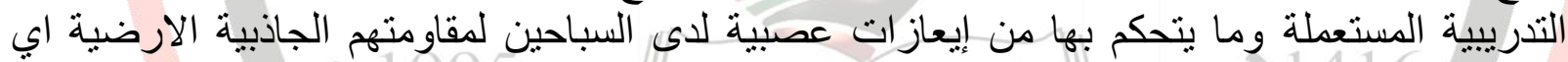

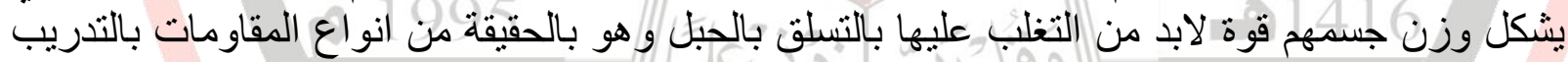

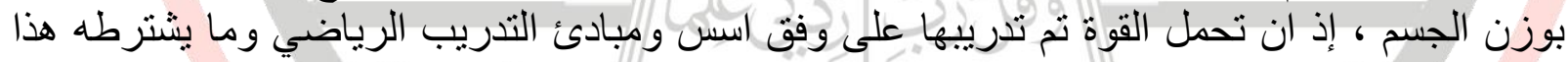

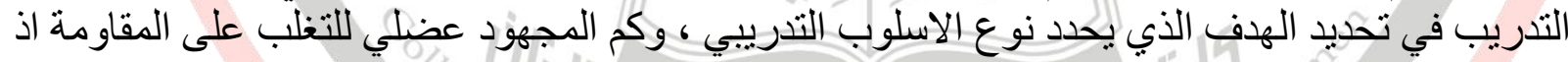

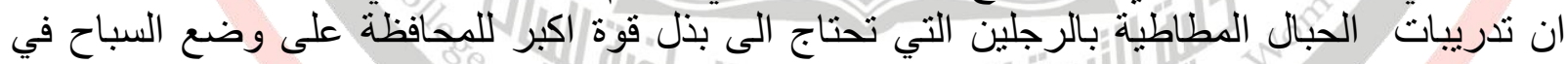

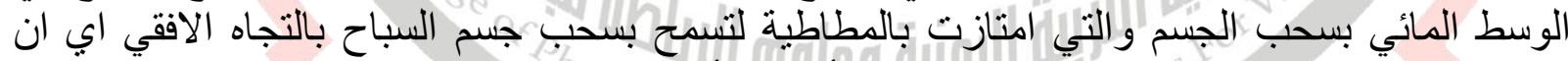

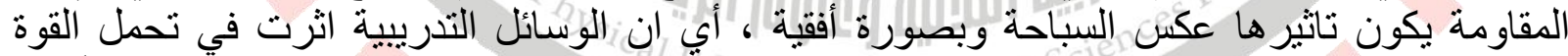

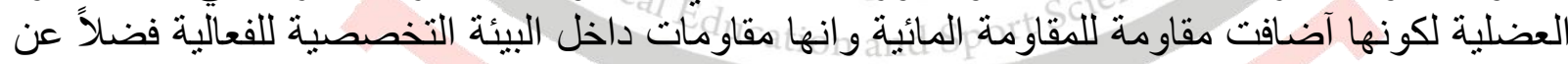

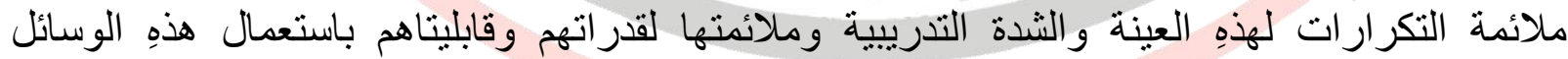

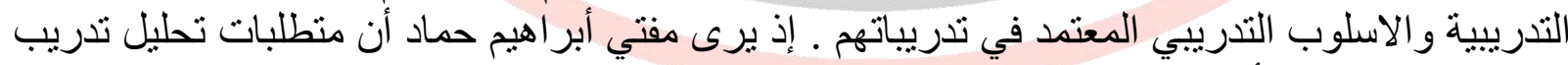

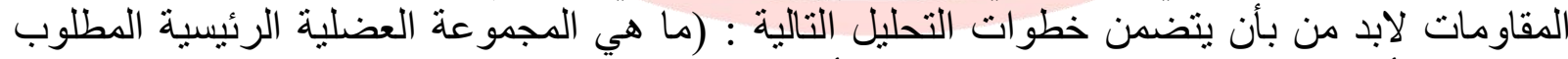

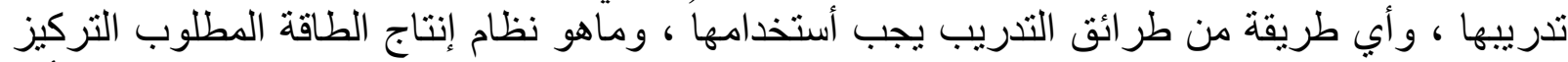

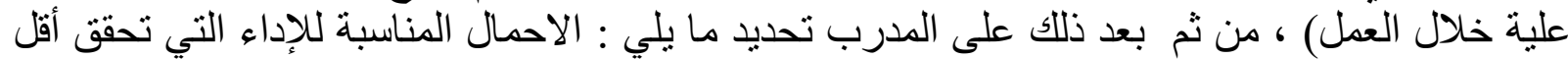

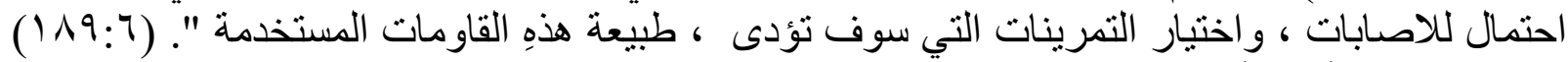

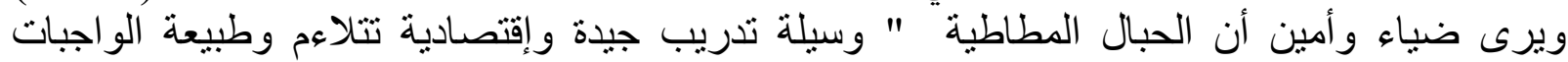
التدرييية في نفس الوقت لتنمية الصفات البدنية كالقوة و التحمل و الاطالة و المرونة". 


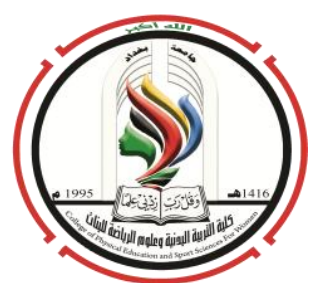

\section{مجلة الرياضة المعاصرة}

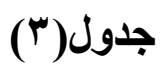

يُبين نتائج أختبار (t-test) الاختبارات القبلية والبعدية للإنجازين

\begin{tabular}{|c|c|c|c|c|c|c|c|c|c|c|c|}
\hline \multirow{2}{*}{ 可 } & \multirow{2}{*}{ (Sig) } & \multirow{2}{*}{ المحسو } & \multirow[t]{2}{*}{ ع ف } & \multirow[t]{2}{*}{ فت } & \multicolumn{2}{|c|}{ الاختبار ألبعدي } & \multicolumn{2}{|c|}{ الاختبار } & \multirow{2}{*}{\multicolumn{3}{|c|}{ الاختباران وعدد العينة }} \\
\hline & & & & & $\varepsilon+$ & سن & $\varepsilon+$ & سنَ & & & \\
\hline دال| & $\cdot, \ldots$ & $\mid r, \leqslant 0 \wedge$ & $\cdot, 1 \% \Lambda$ & $\cdot, V V$ & $\therefore$, Vo & $r, \leqslant 0$ & $\cdot, .9 \mathrm{~V}$ & $\varepsilon, Y Y$ & 0 & ج & 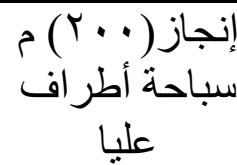 \\
\hline دال & $\cdot, \cdot T V$ & $r, \leqslant r)$ & $\cdot, T Y E$ & $\cdot r \leqslant r$ & $(, ., 0)$ & $r, \varepsilon \wedge$ & $\cdot, 1 \wedge \varepsilon$ & $r, v \tau$ & 0 & ج & 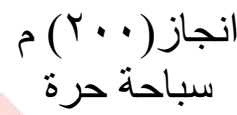 \\
\hline
\end{tabular}

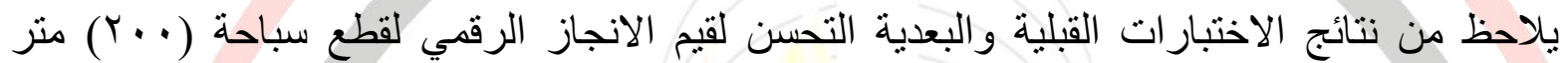

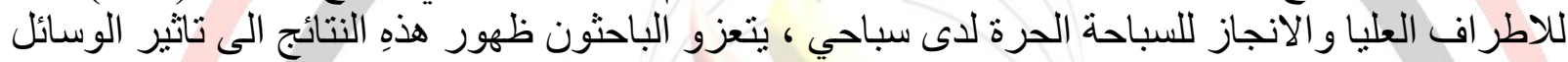

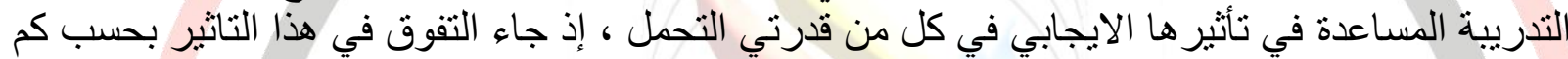

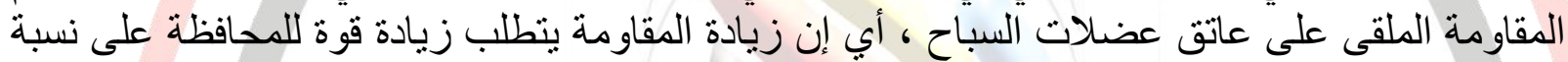

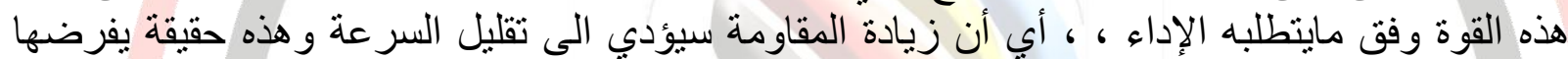

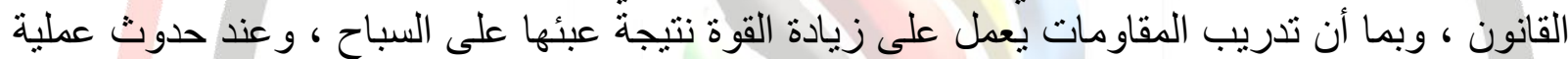

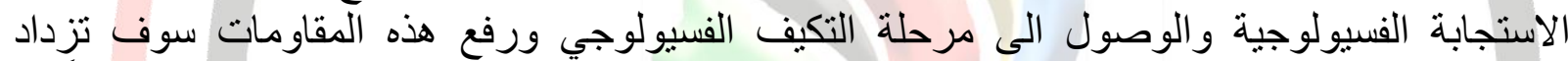

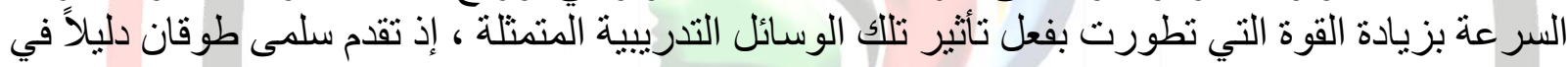

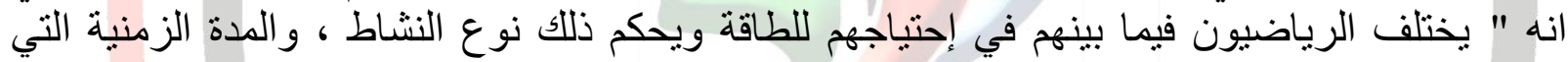

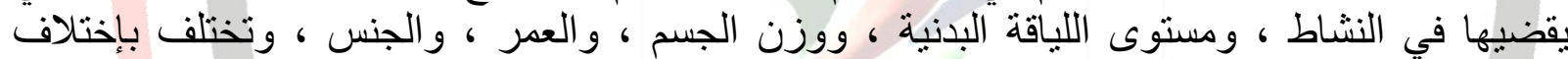

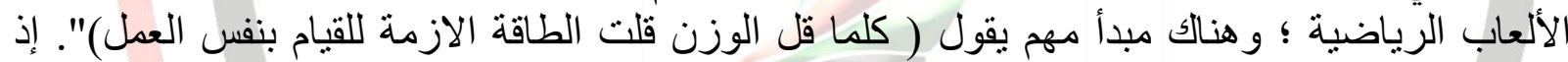

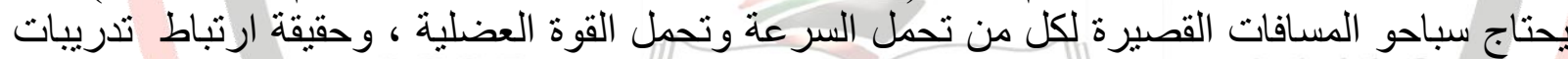

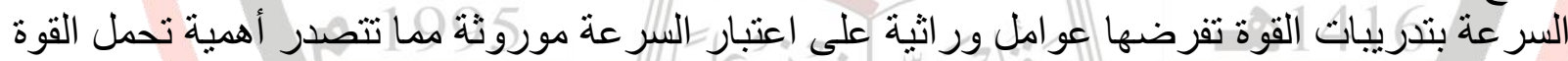

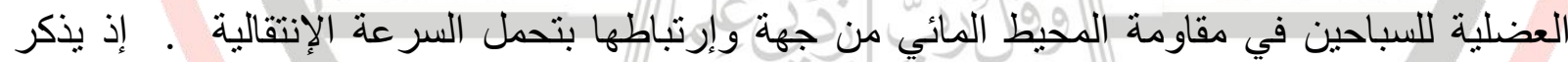

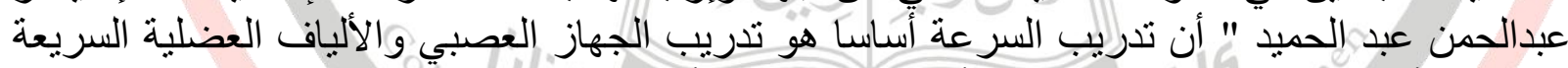

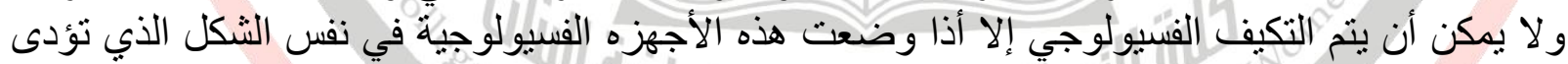

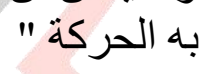

$$
\text { ؟ - الخاتمة }
$$

$$
\text { حيث استتنج الباحثون التالي }
$$

بعد معالجة النتائج المستخلصة إحصائياً و عرضهاو وناقثنتها ، توصل الباحثون إلى الإستتناجات الآتية :-

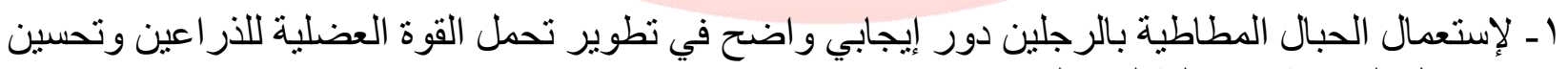
تحمل السر عة الانتقالية لدى السباحين.

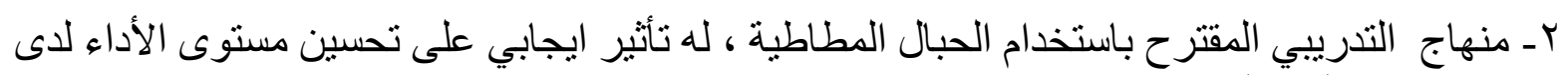
و الانجاز لاى السباحيين 


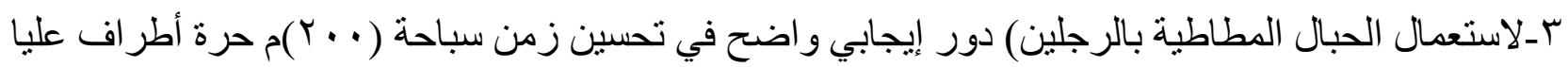

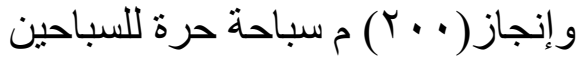
واوصى الباحثون بما يلي ماني على وفق ما توصلت إليه الدر اسة من إستتناجات وضع الباحثثن جملة من التوصيات الآتية و التي لابد من

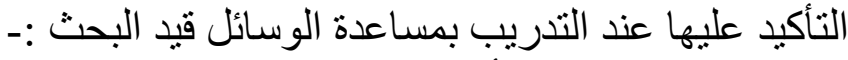

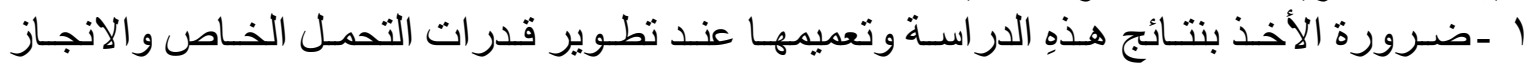
اللسباحين r ـ من الضروري تعريف مدربي السباحة بأهمية كيفية استعمال الوسائل التدرييية اوحسن توظيفها

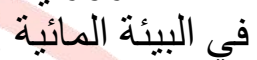

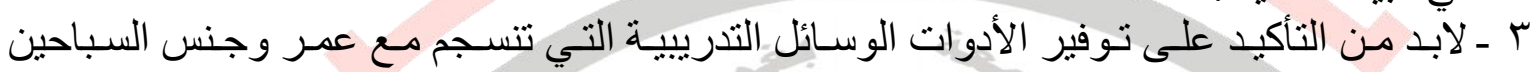

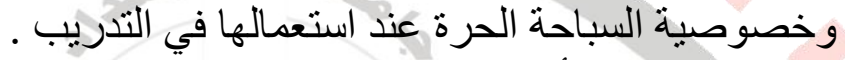
ع ـ من الضروري التأكيد على دور المدرب وزيادة إلمامه بتأثير اتجاه المقاومات وحسب كل وسيلة

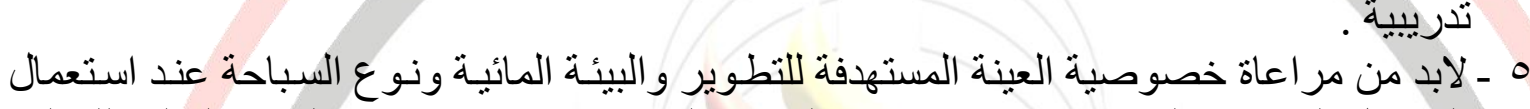

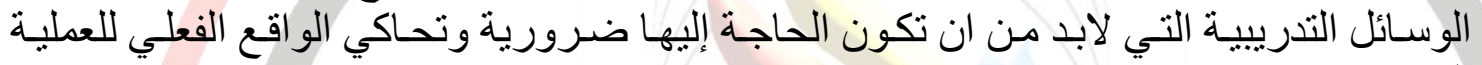

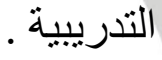

\section{المصادر}

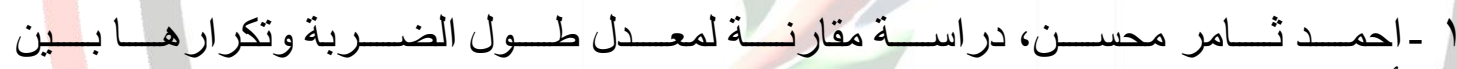

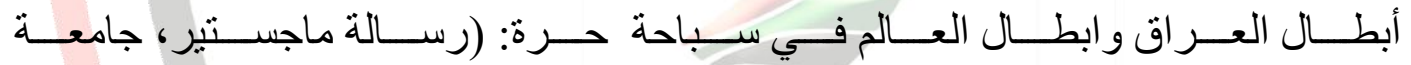

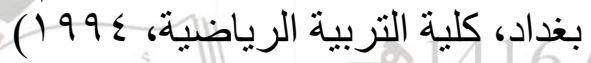

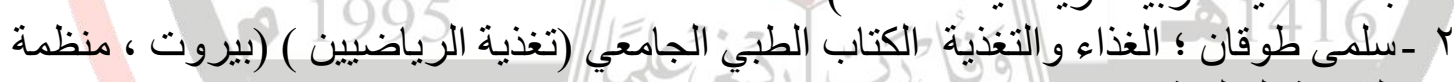
r ـ عبد الرحمن عبد الحميد زاهر ؛ فسيولوجيا مسابقات الوثب و الققز ( القاهرة ، مركز الكتاب للنشر

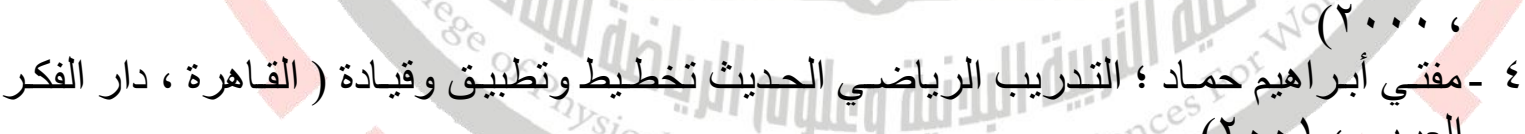
ه ـ أبو العلا أحمد ، أحمد نصر الدين ؛ فنتــئولوجيا اللباقة البدنية ، القاهرة ، دار الفكر العربي ، . ( r...r

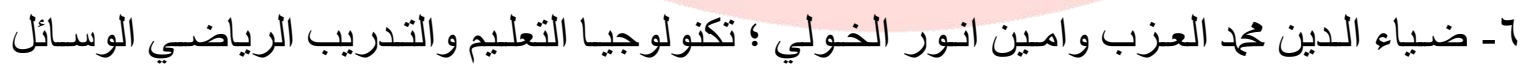
و الكو اد التعليمية_الاجهزة ومساعدات التندريب ( القاهرة، دار الفكر العربي التعلي

V - محمد حسن علاوي واسامة كامل راتب ,البحث العلمي في التربية الرياضية وعلم النفس الرياضي ( القاهرة , دار الفكر العربي , 999 (1) 